Article

\title{
Non-Pulse-Leakage 100-kHz Level, High Beam Quality Industrial Grade Nd:YVO Picosecond Amplifier
}

\author{
Zhenao Bai ${ }^{1,2,3,+}$, Zhenxu Bai ${ }^{4,5,+}$, Zhijun Kang ${ }^{1,2}$, Fuqiang Lian ${ }^{1,2}$, Weiran Lin ${ }^{1,2}$ and \\ Zhongwei Fan 1,2,3,6,* \\ 1 Academy of Opto-Electronics, Chinese Academy of Sciences, Beijing 100094, China; \\ baizhenao@hotmail.com (Z.B.); kzjun1221@126.com (Z.K.); aoefiberlaser@126.com (F.L.); \\ linweiran@aoe.ac.cn (W.L.) \\ 2 National Engineering Research Center for DPSSL, Beijing 102211, China \\ 3 Sino-HG Applied Laser Technology Institute Company, Ltd., Tianjin 300304, China \\ 4 National Key Laboratory of Science and Technology on Tunable Laser, Harbin Institute of Technology, \\ Harbin 150001, China; baizhenxu@hotmail.com \\ 5 MQ Photonics Research Centre, Department of Physics and Astronomy, Macquarie University, \\ Sydney, NSW 2109, Australia \\ 6 University of Chinese Academy of Sciences, Beijing 100049, China \\ * Correspondence: fanzhongwei@aoe.ac.cn; Tel.: +86-10-8217-8609 \\ $\dagger$ These authors contributed equally to this work.
}

Academic Editor: Federico Pirzio

Received: 27 April 2017; Accepted: 26 May 2017; Published: 14 June 2017

\begin{abstract}
A non-pulse-leakage optical fiber pumped 100-kHz level high beam quality $\mathrm{Nd} \mathrm{YVO}_{4}$ picosecond amplifier has been developed. An $80 \mathrm{MHz}, 11.5$ ps mode-locked picosecond laser is used as the seed with single pulse energy of $1 \mathrm{~nJ}$. By harnessing the double $\beta-\mathrm{BaB}_{2} \mathrm{O}_{4}(\mathrm{BBO})$ crystal Pockels cells in both the pulse picker and regenerative amplifier, the seed pulse leakage of the output is suppressed effectively with an adjustable repetition rate from 200 to $500 \mathrm{kHz}$. Through one stage traveling-wave amplifier, a maximum output power of $24.5 \mathrm{~W}$ is generated corresponding to the injected regenerative amplified power of $9.73 \mathrm{~W}$ at $500 \mathrm{kHz}$. The output pulse duration is $16.9 \mathrm{ps,}$ and the beam quality factor $M^{2}$ is measured to be 1.25 with near-field roundness higher than $99 \%$ at the full output power.
\end{abstract}

Keywords: regenerative amplifier; double-crystal Pockels cell; 100-kHz; non-pulse-leakage

\section{Introduction}

Over the past decade, there has been significant development of high power ultrashort pulse lasers with high repetition rate [1-3], with applications including nonlinear optical frequency conversion, precise material processing, satellite ranging, and high-intensity physics [4-7]. Specifically, in ultrashort lasers in the order of picoseconds, their pulse width is smaller than the electron-phonon coupling time of most materials, heat conduction can be decreased substantially during the process of interaction. This decrease is beneficial to fine processing, biological medicine, and historical relic cleaning [8-11]. Currently, mode-locking is the main approach to obtain the pulse width around 10 ps. However, the pulse energy of the directly generated mode-locked lasers is very low such that it restricts their applications. To solve this problem, different types of laser amplifiers are utilized, in which a regenerative amplifier is considered to be the most effective method for strong amplification of the mode-locked pulses $[1,2,12,13]$. In most cases, increasing the repetition rate and power can improve the efficiency of laser processing and laser ranging. Therefore, it is not only necessary to increase the single 
pulse energy but also the repetition rate of the current regenerative amplified lasers. Determined by the parameters of Pockels cell and regenerative cavity, repetition rates from hundreds to mega-Hz have been obtained with output power up to 100 watts. For instance, $\mathrm{Nd}: \mathrm{YVO}_{4}$ picosecond regenerative amplifiers with a repetition rate up to $850 \mathrm{kHz}$ have been demonstrated [14,15]; other broadband gain materials such as $\mathrm{Yb}: \mathrm{CaF}_{2}, \mathrm{Yb}: \mathrm{CAlGO}, \mathrm{Yb}: \mathrm{YVO}_{4}$, and $\mathrm{Nd}: \mathrm{LuVO}_{4}$ show up to $1.43 \mathrm{MHz}$ repetition rate [16-18]. Currently, Bergmann et al. [19] reported the record high repetition rate of $2 \mathrm{MHz}$ for a picosecond regenerative amplifier in Yb:YAG. In general, when the repetition rate is up to $100 \mathrm{kHz}$, it is very difficult for the Pockels cell to realize the fast and complete switching due to the limitations of high voltage driving supply. This will lead to the leakage of the directly amplified seed pulses in the output that not only introduce optical noise but also increase unnecessary pump power consumption. Especially after traveling-wave amplification, the existence of pulse leakage will further reduce the master-slave pulse ratio of the output and influence the performance of the laser system in applications. For example, in nonmetallic brittle materials processing (viz. artificial crystal, ceramics, and solar panels), the amplified leaking pulses easily cause breakage of the samples because of the excessive heat load; meanwhile, the presence of leaked pulses also results in the reduction of accuracy in laser satellite ranging and laser communication due to the introduction of stray signals. Therefore, it is necessary to eliminate the pulse leakage of regenerative amplifiers used in some specific industrial areas.

$\mathrm{Nd}: \mathrm{YVO}_{4}$ crystals as a gain material with sufficient gain bandwidth and a high emission cross section are widely adopted in end-pumping picosecond regenerative amplifiers. Nowadays, fiber coupled high-power laser diode (LD) are an appropriate pumping source for the regenerative amplifier due to their highly compact size and relatively low cost. The pumping of $\mathrm{Nd}$ : $\mathrm{YVO}_{4}$ with $888 \mathrm{~nm} \mathrm{LD}$ induces less thermal stress gradient along the crystal compared with $808 \mathrm{~nm}$ that makes it possible for long time operation of the laser with higher stability [20,21]. Table 1 presents the physical parameters of $\mathrm{Nd}: \mathrm{YVO}_{4}$ crystal pumped by $808 \mathrm{~nm}$ and $888 \mathrm{~nm}$ wavelengths [22,23]. As the data show, the lower fractional thermal loading in $888 \mathrm{~nm}$ pump compared with $808 \mathrm{~nm}$ wavelength results in the heat reduction and optical efficiency growth. Although the absorption coefficient of $808 \mathrm{~nm}$ is higher compared to $888 \mathrm{~nm}$ wavelength, it shows different values between the two crystallographic axes that result in the varying and irreproducible absorption if without the polarization controlling of pump light. The lower pump absorption efficiency can be optimized by using a longer crystal for high output power that allows the heat load to be spread in a larger volume, thus minimizing stress and thermal gradient [24]. Additionally, the $888 \mathrm{~nm}$ wavelength shows a higher absorption band width than $808 \mathrm{~nm}$, which decreases the sensitivity to the shift in the pump wavelength.

Table 1. Comparison of $\mathrm{Nd}: \mathrm{YVO}_{4}$ pumped by $808 \mathrm{~nm}$ and $888 \mathrm{~nm}$.

\begin{tabular}{ccccc}
\hline Wavelength (nm) & $\begin{array}{c}\text { Output Wavelength } \\
(\mathbf{n m})\end{array}$ & Fractional Thermal Loading & $\begin{array}{c}\text { Absorption Coefficient } \\
\left(\mathbf{c m}^{-\mathbf{1}}\right)\end{array}$ & $\begin{array}{c}\text { Absorption Band Width } \\
(\mathbf{n m})\end{array}$ \\
\hline 808 & 1064 & 0.241 & $10(a$-axis $) 37(c$-axis $)$ & 0.8 \\
888 & 1064 & 0.173 & $1.5(a-\& c$-axis $)$ & 3 \\
\hline
\end{tabular}

In this study, we demonstrate a highly stable and high power industrial grade picosecond $\mathrm{Nd}: \mathrm{YVO}_{4}$ amplifier with the adjustable repetition rate from 200 to $500 \mathrm{kHz}$. A combination of an $888 \mathrm{~nm}$ optical fiber pumped $\mathrm{Nd}: \mathrm{YVO}_{4}$ regenerative and a traveling-wave amplifiers have been utilized. To eliminate the leakage of the regenerative amplifier in high repetition rate operation, double BBO crystal Pockels cells are adopted as one switch to improve the responsivity of the switching. The maximum output power of $24.5 \mathrm{~W}$ is obtained at $500 \mathrm{kHz}$ with the pulse width of $16.9 \mathrm{ps}$, corresponding to the pulse energy and the peak power of $0.05 \mathrm{~mJ}$ and $2.9 \mathrm{MW}$, respectively. The beam quality factor $M^{2}$ is measured to be 1.25 at the full power operation. When operated at $200 \mathrm{kHz}$, the maximum pulse energy of $0.11 \mathrm{~mJ}$ and the maximum peak power of $6.5 \mathrm{MW}$ is obtained. Our measurements show that this method effectively realizes the suppression of leakage and improves the purity of the regenerative amplified pulses. 


\section{Experimental Principle and Setup}

Q-switch is the core component of the regenerative amplifier that is used in the pulse picker for mode-locked sequence. To date, both acousto- and electro-optic switches have been used to realize the pulse selection function in regenerative amplifiers $[19,25,26]$. However, due to the slow switching speed (with rise time up to 100 nanoseconds) and limited diffraction efficiency (usually less than $90 \%$ ), the acousto-optic switch is difficult to generate regenerative pulses without the leakage of mode-locked seed. In contrast to the acousto-optic switch, the electro-optic switch has faster switching speed (rise time $<10 \mathrm{~ns}$ ) and excellent switching effect, which is widely adopted in regenerative amplifiers. Nowadays, the commonly used electro-optic crystals include $\beta-\mathrm{BaB}_{2} \mathrm{O}_{4}(\mathrm{BBO}), \mathrm{KH}_{2} \mathrm{PO}_{4}$ $(\mathrm{KDP}), \mathrm{KD}_{2} \mathrm{PO}_{4}(\mathrm{KD} * \mathrm{P}), \mathrm{RbTiOPO}_{4}(\mathrm{RTP})$, and $\mathrm{LiNbO}_{3}$ (Lithium niobate) etc. To meet different experimental conditions (such as half- or quarter-wavelength voltage, acceptable input beam diameter, and available crystal size), both longitudinal and transverse electrode configuration Pockels cells are manufactured. However, so far there is not one kind of electro-optic crystal or configuration the can provide a general solution under different operating wavelengths, repetition rates, spot diameters, and output powers. At present, BBO crystal Pockels cells with minimal piezoelectric ringing and low acoustic noise, have emerged in high repetition rate $(>100 \mathrm{kHz})$ pulse picking applications $[14-17,19]$. Nevertheless, with the increase of repetition rate, it is difficult to realize fast switching within the effective duty cycle due to the long fall time of the high voltage.

To solve the problem, double BBO crystal Pockels cell is adopted in our experiment to reduce the load of the high voltage driving supply by reducing the quarter-wavelength voltage. The value of the quarter-wavelength voltage $V_{\lambda / 4}$ of $\mathrm{BBO}$ crystal is given by $[27,28]$ :

$$
V_{\lambda / 4}=\frac{\lambda d}{4 n_{0}^{3} d_{22} L}
$$

where laser wavelength $\lambda=1064 \mathrm{~nm}$, the crystal section thickness $d=3 \mathrm{~mm}$, the refractive index of the crystal $n_{0}=1.66$, the effective electro-optic coefficient $d_{22}=2.2 \mathrm{pm} / \mathrm{V}$, and the crystal length $L=40 \mathrm{~mm}$. The calculated value of the quarter-wavelength voltage is just $2000 \mathrm{~V}$, which is almost half that of the previous reports. The lower quarter-wavelength voltage of Pockels cell means faster switching speed, and makes it possible for higher repetition rate operation.

The experimental setup of the picosecond amplifier is shown in Figure 1, which consists of a picosecond seed source, two optical isolators, a BBO pulse picker, a regenerative amplifier, and one stage traveling-wave amplifier.

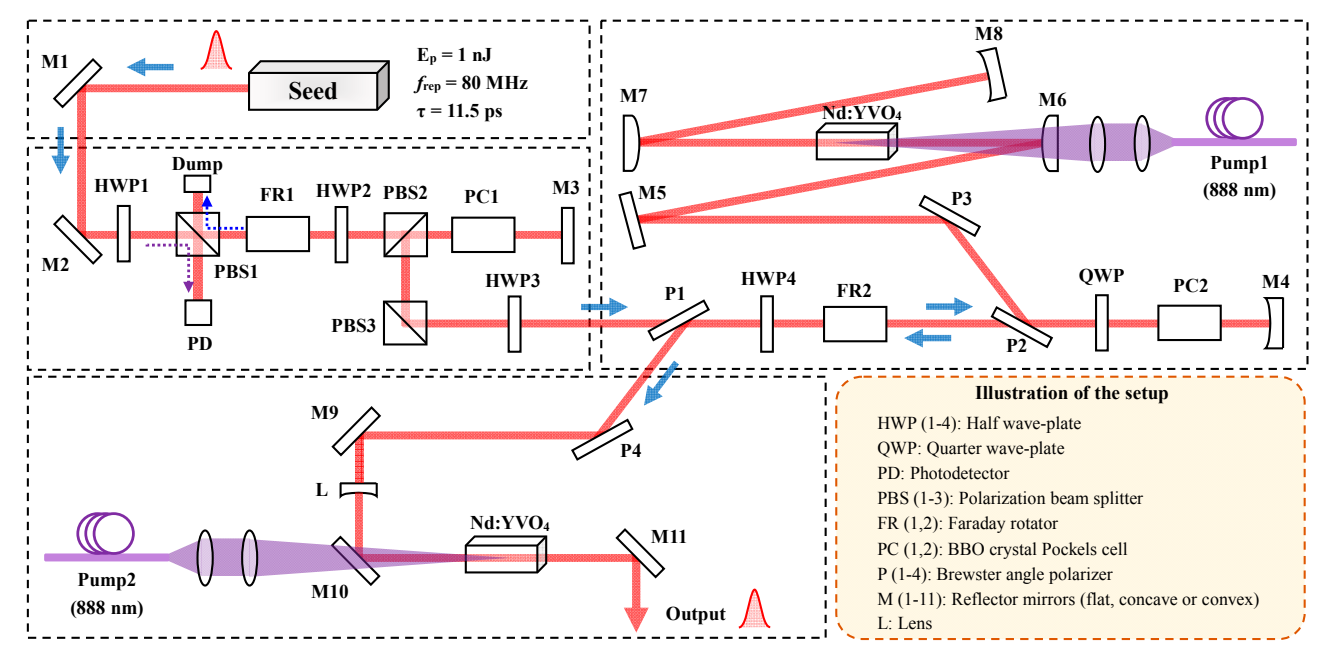

Figure 1. Diagram of the non-leakage 100-kHz Nd:YVO $\mathrm{YV}_{4}$ picosecond regenerative amplifier. The inset is the illustration of the setup. 
In the present system, the amplifier is seeded with a self-developed semiconductor saturable absorption mirror (SESAM) mode-locked oscillator capable of generating 11.5 ps pulses at a repetition rate of $80 \mathrm{MHz}$ with a single pulse energy of $1 \mathrm{~nJ}$. Picosecond pulse sequence from the seed is injected into the pulse picker through two high-reflection mirrors, M1 and M2. The function of the pulse picker is to select the desired repetition rate for regenerative amplifier by eliminating the pulse leakage of the seed sequence. The half-wave plate HWP1 is set to let most of the seed light to $p$-polarization and the rest s-polarization reflected into the photodetector (PD) as feedback signal. After passing through the first stage optical isolator composed of a polarization beam splitter PBS1, a Faraday rotator FR1, and a HWP2, the seed enters into the double BBO crystal Pockels cell PC1 (PCB3S-1342; EKSMA Optics, Vilnius, Lithuania). The size of the two BBO crystals are $3 \times 3 \times 20 \mathrm{~mm}^{3}$. The distance between the $\mathrm{PC} 1$ and $\mathrm{M} 3$ is $0.8 \mathrm{~m}$, corresponding to a round-trip time about $5.3 \mathrm{~ns}$. Without voltage of the PC1, the reflected seed from the M3 will pass through the PBS2 and FR1, then enter into the dump. While with a quarter-wavelength voltage of the $\mathrm{PC} 1$, the pulse sequence with a specified range of repetition rate can be selected with polarization changed to s-polarization after double-passing through PC1 and then output by the PBS2. The switching time of the two Pockels cells in our setup is adjustable from 25 to $200 \mathrm{~ns}$ with a rising and falling time about $5 \mathrm{~ns}$. The switch time of the PC1 is set to be $20 \mathrm{~ns}$. With the polarization changed to $p$-polarization by HWP3, the selected pulses enter into the regenerative amplifier. The second optical isolator formed by a Brewster angle polarizer P1, HWP4, and FR2 is placed in front of the regenerative amplifier which is used to output the regenerative amplified pulse.

The laser pulse with $p$-polarization is injected into the regenerative amplifier by the P2. The length of the whole cavity is $1.8 \mathrm{~m}$, corresponding to a cavity round-trip time of $12 \mathrm{~ns}$. The gain medium is 0.5 at. \% doped $\mathrm{Nd}: \mathrm{YVO}_{4}$ with a size of $3 \times 3 \times 20 \mathrm{~mm}^{3}$ and double-end-wedged cut at $2^{\circ}$. Both sides of the Nd: $\mathrm{YVO}_{4}$ have anti-reflective (AR) coating at the $1064 \mathrm{~nm}$ and $888 \mathrm{~nm}$ wavelength. A $50 \mathrm{~W}$, $888 \mathrm{~nm}$ fiber-coupled laser diode with a numerical aperture of 0.22 and a diameter of $400 \mu \mathrm{m}$ is used as the pump source. The coupling ratio of the pump beam is 1:3 into the $\mathrm{Nd}: \mathrm{YVO}_{4}$ crystal. M4 and M8 are two concave mirrors with $\mathrm{R}=-2000 \mathrm{~mm}$; M4 and M7 are two $1064 \mathrm{~nm}$ high-reflection (HR) convex mirrors with $\mathrm{R}=1500 \mathrm{~mm}$ in which M4 is also $888 \mathrm{~nm}$ AR coated. Reflected by an end mirror M4, the seed beam double passes the quarter-wave plate (HWP) and reflects through P2 with s-polarization. Then the PC2 inside the cavity is switched on with a quarter-wavelength voltage and the seed laser continues to make round trips in the regenerative cavity with s-polarization until the PC2 is switched off. The regenerative amplified pulses are reflected by P1 with s-polarization, and then enter into the traveling-wave amplifier.

To further amplify the output power, one stage traveling-wave $\mathrm{Nd}: \mathrm{YVO}_{4}$ amplifier is adopted. A Nd: $\mathrm{YVO}_{4}$ crystal with the dimensions of $4 \times 4 \times 30 \mathrm{~mm}^{3}$ is selected as gain medium with 0.5 at. $\% \mathrm{Nd}^{3+}$-doped and at a $2^{\circ}$ angle. The pumping source of the traveling-wave amplifier has the same parameters as the regenerative amplifier with a coupling ratio of 1:4. $\mathrm{L}$ is a concave lens with $\mathrm{f}=-360 \mathrm{~mm}$ used to compensate the thermal lens effect of the Nd:YVO 4 crystal. M10 and M11 are two $888 \mathrm{~nm}$ AR \& $1064 \mathrm{~nm}$ HR coated $45^{\circ}$ plane mirror. The single-pass amplified pulse is output from the M11.

\section{Experimental Results and Discussion}

In our experiment, we tested the leakage of the regenerative amplifier by monitoring the output power with the PC2 turning on and off. At the maximum pump power of $50 \mathrm{~W}$, the output power of the regenerative amplifier increases with the Pockels cells switching time, however, the leakage appears when the PC2 switching time more than 69 ns. For example, with the switching time of $79 \mathrm{~ns}$, the leakage reached $2 \mathrm{~W}$ when the maximum regenerative amplified power was about $18 \mathrm{~W}$ at $500 \mathrm{kHz}$. Accordingly, in order to obtain maximum power regenerative output without leakage, the switching time of Pockels cells is set to be $68 \mathrm{~ns}$, corresponding to the five round trips in the regenerative cavity. The pump power of the regenerative amplifier is set to be $50 \mathrm{~W}$ because higher power may result in the self-excited oscillation between the M4 and M8. Next, improvement of the leakage and self-excited 
oscillation threshold to increase the output power of regenerative amplifier will be studied, including the optimization of cavity design and Pockels cell structure (e.g., employing bidirectional voltage switching power supply to achieve a faster and more thorough switch [29]).

The injected pulse energy into the regenerative amplifier was about $1 \mathrm{~nJ}$, and the output pulse energy saturated with the increase number of round trips in the cavity. Figure $2 a, b$ illustrates the dependence of the output power and pulse energy of the regenerative and final amplifier output on the repetition rate from 200 to $500 \mathrm{kHz}$, respectively. At the same pump power, the out power of the regenerative amplifier increases with the repetition rate, while the single pulse energy decreases, which is shown in Figure 2a. At $500 \mathrm{kHz}$, maximum regenerative amplified power of $9.73 \mathrm{~W}$ was obtained corresponding to the pulse energy of $0.02 \mathrm{~mJ}$. After passing through the traveling-wave amplifier, the maximum output power of the laser system was $24.5 \mathrm{~W}$ at $500 \mathrm{kHz}$, corresponding to the peak power of $2.9 \mathrm{MW}$; while the maximum output pulse energy obtained was $0.11 \mathrm{~mJ}$ at $200 \mathrm{kHz}$, corresponding to the peak power of $6.5 \mathrm{MW}$. No leakage occurred when the repetition rate continuously adjusting from 200 to $500 \mathrm{kHz}$ with the measured root-mean-square-error (RMSE) of output power less than $0.04 \%$.
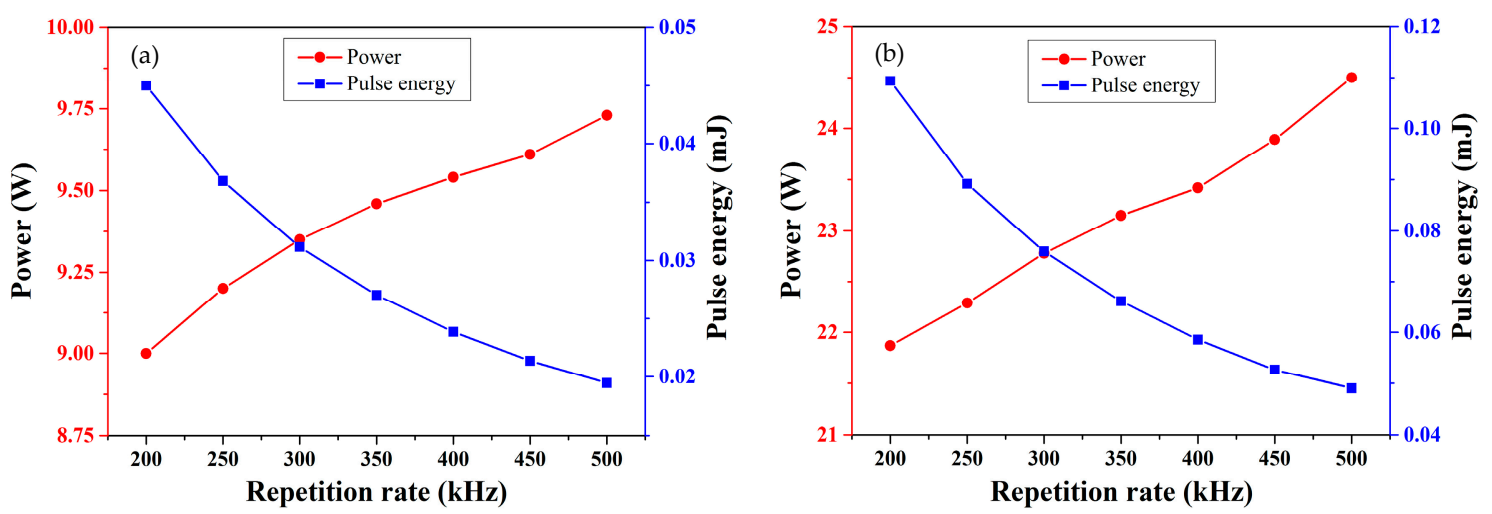

Figure 2. Average output power and pulse energy of the amplifier in dependence on the repetition rate of (a) regenerative amplifier output; and (b) final amplifier output.

The amplified pulses are monitored using a photodiode. At $500 \mathrm{kHz}$, oscilloscope trace of the output pulse train with $4 \mu \mathrm{s} / \mathrm{div}$ and single pulse with $10 \mathrm{~ns} /$ div are illustrated in Figure 3, respectively. We can observe that the amplifier generates very clean output pulses without any noticeable pulse fluctuation or stray signal.
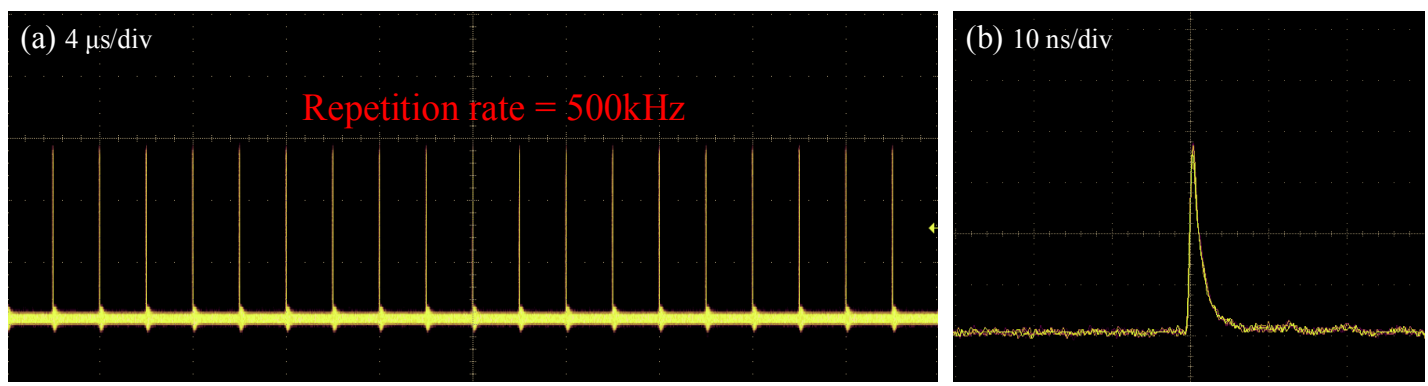

Figure 3. Oscilloscope trace of the regenerative amplified pulse train (a) $4 \mu \mathrm{s} /$ div; and (b) $10 \mathrm{~ns} /$ div.

Figure 4a shows the autocorrelation trace of the amplified pulses with the measured width of 16.9 ps at a repetition rate of $500 \mathrm{~Hz}$. The pulse width of the output was slightly broadened compared with that of the seed pulses $11.5 \mathrm{ps}$, which is mainly caused by the gain narrowing [30,31]. The measured beam quality factor $M^{2}$ and near-field beam intensity profile are shown in Figure $4 \mathrm{~b}$. 
The $M^{2}$ measured were 1.27 and 1.22 for the horizontal and vertical axes of the output, respectively. The roundness of the near-field intensity distribution is higher than $99 \%$.
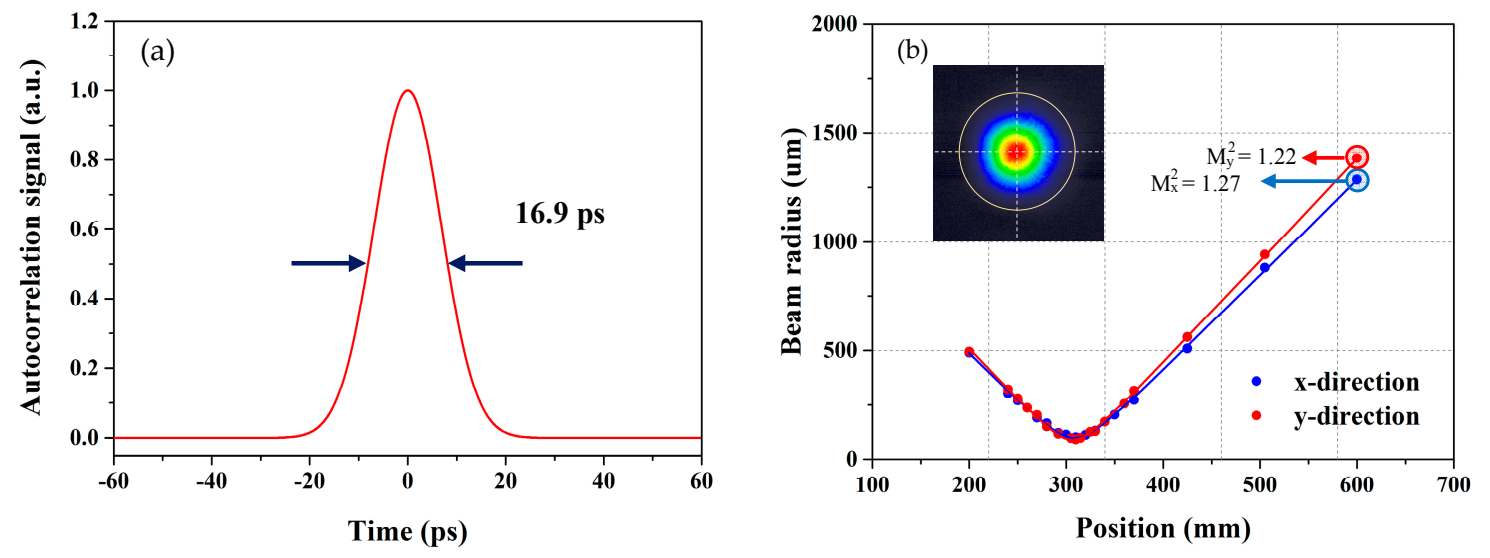

Figure 4. Measured (a) autocorrelation trace (Gaussian fitting) for the amplified pulse; and (b) beam quality factor $M^{2}$ (insert: near-field beam intensity distribution).

\section{Conclusions}

In conclusion, we have demonstrated a non-pulse-leakage high power industrial grade $\mathrm{Nd}: \mathrm{YVO}_{4}$ picosecond amplifier. Two double BBO crystal Pockels cells were used in the pulse picker and regenerative amplifier, respectively. This design successfully suppresses the appetence of pulse leakage in the regenerative amplifier that improved the purity of the output pulses, which makes it possible for the regenerative amplifier to operate stably at the repetition rate of $100-\mathrm{kHz}$ level with lower high voltage driving supply. A maximum power of $24.5 \mathrm{~W}$ was obtained at $500 \mathrm{kHz}$, and a maximum single pulse energy $0.11 \mathrm{~mJ}$ was obtained at $200 \mathrm{kHz}$. High beam quality output is obtained with $M^{2}$ about 1.25 and the roundness of near-field distribution up to $99 \%$. The output pulse width measured to be 16.9 ps with the RMSE of the output is less than $0.04 \%$. Our work offers a new approach to generate high quality (in both time domain and space domain) 100-kHz level repetition rate continuous adjustable picosecond regenerative amplified output. This solution can be made possible with high efficiency and high precision processing for nonmetallic brittle materials, as well as low noise space communication.

Acknowledgments: This work was supported by the Development of High Power Nanosecond Laser \& Precision Detecting Instrument Foundation (Grant No. ZDYZ2013-2) and China Innovative Talent Promotion Plans for Innovation Team in Priority Fields (Grant No. 2014RA4051). We also acknowledge Mojtaba Moshkani (Macquarie University) for his helpful comments.

Author Contributions: We confirm that all authors contributed substantially to the reported work. Zhenao Bai was the originator of the idea of this study and conceived most of the experiments; Zhenxu Bai performed the experiments and wrote the manuscript under the supervision of Zhenao Bai and Zhongwei Fan; Zhijun Kang, Fuqiang Lian, and Weiran Lin participated in the research design and analyzed the data; Zhongwei Fan supervised the research and provided the facilities. All the authors discussed and interpreted the results. All the authors read the final manuscript.

Conflicts of Interest: The authors declare no conflict of interest.

\section{References}

1. Siebold, M.; Hornung, M.; Hein, J.; Paunescu, G.; Sauerbrey, R.; Bergmann, T.; Hollemann, G. A high-average-power diode-pumped $\mathrm{Nd}: \mathrm{YVO}_{4}$ regenerative laser amplifier for picosecond-pulses. Appl. Phys. B 2004, 78, 287-290. [CrossRef]

2. Metzger, T.; Schwarz, A.; Teisset, C.Y.; Sutter, D.; Killi, A.; Kienberger, R.; Krausz, F. High-repetition-rate picosecond pump laser based on a Yb:YAG disk amplifier for optical parametric amplification. Opt. Lett. 2009, 34, 2123-2125. [CrossRef] [PubMed] 
3. Röser, F.; Eidam, T.; Rothhardt, J.; Schmidt, O.; Schimpf, D.N.; Limpert, J.; Tünnermann, A. Millijoule pulse energy high repetition rate femtosecond fiber chirped-pulse amplification system. Opt. Lett. 2007, 32, 3495-3497. [CrossRef] [PubMed]

4. Zhang, Z.; Zhang, H.; Wu, Z.; Chen, J.; Li, P.; Yang, F. kHz repetition Satellite Laser Ranging system with high precision and measuring results. Chin. Sci. Bull. 2011, 56, 1177-1183. [CrossRef]

5. Bai, Z.; Cui, C.; Liu, Z.; Yuan, H.; Wang, H.; Wang, Y.; Lu, Z. Drilling study on Cu, Mo, W and Ti by using SBS pulse compressed steep leading edge hundred picoseconds laser. Optik 2016, 127, 11156-11160. [CrossRef]

6. Surmeneva, M.; Nikityuk, P.; Hans, M.; Surmenev, R. Deposition of Ultrathin Nano-Hydroxyapatite Films on Laser Micro-Textured Titanium Surfaces to Prepare a Multiscale Surface Topography for Improved Surface Wettability/Energy. Materials 2016, 9, 862. [CrossRef]

7. Je, G.; Malka, D.; Kim, H.; Hong, S.; Shin, B. A study on micro hydroforming using shock wave of $355 \mathrm{~nm}$ UV-pulsed laser. Appl. Surf. Sci. 2017, in press. [CrossRef]

8. Niemz, M.H.; Klancnik, E.G.; Bille, J.F. Plasma-mediated ablation of corneal tissue at $1053 \mathrm{~nm}$ using a Nd:YLF oscillator/regenerative amplifier laser. Lasers Surg. Med. 1991, 11, 426-431. [CrossRef] [PubMed]

9. Chichkov, B.N.; Momma, C.; Nolte, S.; Von Alvensleben, F.; Tünnermann, A. Femtosecond, picosecond and nanosecond laser ablation of solids. Appl. Phys. A 1996, 63, 109-115. [CrossRef]

10. Biswas, S.; Karthikeyan, A.; Kietzig, A.M. Effect of Repetition Rate on Femtosecond Laser-Induced Homogenous Microstructures. Materials 2016, 9, 1023. [CrossRef]

11. Elnaggar, A.; Fitzsimons, P.; Lama, A.; Fletcher, Y.; Antunes, P.; Watkins, K.G. Feasibility of ultrafast picosecond laser cleaning of soiling on historical leather buckles. Herit. Sci. 2016, 4, 30. [CrossRef]

12. Dorrer, C.; Consentino, A.; Irwin, D.; Qiao, J.; Zuegel, J.D. OPCPA front end and contrast optimization for the OMEGA EP kilojoule, picosecond laser. J. Opt. 2015, 17, 094007. [CrossRef]

13. Chen, Y.; Liu, K.; Yang, J.; Yang, F.; Gao, H.W.; Zong, N.; Yuan, L.; Lin, Y.Y.; Liu, Z.; Peng, Q.J.; et al. 8.2 mJ, $324 \mathrm{MW}, 5 \mathrm{kHz}$ picosecond MOPA system based on Nd: YAG slab amplifiers. J. Opt. 2016, 18, 075503. [CrossRef]

14. Lührmann, M.; Harth, F.; Theobald, C.; Ulm, T.; Knappe, R.; Nebel, A.; Klehr, A.; Erbert, G.; L'huillier, J. High average power $\mathrm{Nd}: \mathrm{YVO}_{4}$ regenerative amplifier seeded by a gain switched diode laser. Proc. SPIE 2011, 7912, 791210.

15. Bai, Z.; Fan, Z.; Lian, F.; Tan, T.; Bai, Z.; Yang, C.; Kang, Z.; Liu, C. High power 888 nm optical fiber end-pumped $\mathrm{Nd}: \mathrm{YVO}_{4}$ picosecond regenerative amplifier at hundreds kHz. Proc. SPIE 2016, 10152, 101520 S.

16. Caracciolo, E.; Kemnitzer, M.; Guandalini, A.; Pirzio, F.; Agnesi, A.; der Au, J.A. High pulse energy multiwatt $\mathrm{Yb}: \mathrm{CaAlGdO}_{4}$ and $\mathrm{Yb}: \mathrm{CaF}_{2}$ regenerative amplifiers. Opt. Express 2014, 22, 19912-19918. [CrossRef] [PubMed]

17. Rudenkov, A.; Kisel, V.; Matrosov, V.; Kuleshov, N. 200 kHz 5.5 W Yb ${ }^{3+}: \mathrm{YVO}_{4}$-based chirped-pulse regenerative amplifier. Opt. Lett. 2015, 40, 3352-3355. [CrossRef] [PubMed]

18. Gao, P.; Lin, H.; Li, J.; Guo, J.; Yu, H.; Zhang, H.; Liang, X. Megahertz-level, high-power picosecond Nd: $\mathrm{LuVO}_{4}$ regenerative amplifier free of period doubling. Opt. Express 2016, 24, 13963-13970. [CrossRef] [PubMed]

19. Bergmann, F.; Siebold, M.; Loeser, M.; Röser, F.; Albach, D.; Schramm, U. MHz Repetion Rate Yb: YAG and $\mathrm{Yb}: \mathrm{CaF}_{2}$ Regenerative Picosecond Laser Amplifiers with a BBO Pockels Cell. Appl. Sci. 2015, 5, 761-769. [CrossRef]

20. McDonagh, L.; Wallenstein, R.; Nebel, A. 111 W, 110 MHz repetition-rate, passively mode-locked TEM 00 $\mathrm{Nd}: \mathrm{YVO}_{4}$ master oscillator power amplifier pumped at $888 \mathrm{~nm}$. Opt. Lett. 2007, 32, 1259-1261. [CrossRef] [PubMed]

21. Bai, Z.A.; Fan, Z.W.; Bai, Z.X.; Lian, F.Q.; Kang, Z.J.; Lin, W.R. Optical fiber pumped high repetition rate and high power Nd: $\mathrm{YVO}_{4}$ picosecond regenerative amplifier. Appl. Sci. 2015, 5, 359-366. [CrossRef]

22. McDonagh, L.; Wallenstein, R.; Knappe, R.; Nebel, A. High-efficiency $60 \mathrm{~W} \mathrm{TEM}_{00} \mathrm{Nd} \mathrm{YVO}_{4}$ oscillator pumped at $888 \mathrm{~nm}$. Opt. Lett. 2006, 31, 3297-3299. [CrossRef] [PubMed]

23. Bai, Z.A.; Fan, Z.W.; Lian, F.Q.; Bai, Z.X.; Kan, Z.J.; Zhang, J. 20 W passive mode-locked picosecond oscillator. Proc. SPIE 2014, 9281, 92812M.

24. McDonagh, L.; Knappe, R.; Nebel, A.; Wallenstein, R. $888 \mathrm{~nm}$ pumping of $\mathrm{Nd}: \mathrm{YVO}_{4}$ for high-power high-efficiency TEM 00 lasers. Proc. SPIE 2017, 6451, 64510F. 
25. Delaigue, M.; Manek-Hönninger, I.; Salin, F.; Hönninger, C.; Rigail, P.; Courjaud, A.; Mottay, E. 300 kHz femtosecond $\mathrm{Yb}$ : KGW regenerative amplifier using an acousto-optic Q-switch. Appl. Phys. B 2006, 84, 375-378. [CrossRef]

26. Liu, J.; Wang, W.; Wang, Z.; Lv, Z.; Zhang, Z.; Wei, Z. Diode-Pumped High Energy and High Average Power All-Solid-State Picosecond Amplifier Systems. Appl. Sci. 2015, 5, 1590-1602. [CrossRef]

27. Roth, M.; Tseitlin, M.; Angert, N. Oxide crystals for electro-optic Q-switching of lasers. Glass Phys. Chem. 2005, 31, 86-95. [CrossRef]

28. Peng, Z.; Chen, M.; Yang, C.; Chang, L.; Li, G. A cavity-dumped and regenerative amplifier system for generating high-energy, high-repetition-rate picosecond pulses. Jpn. J. Appl. Phys. 2015, 54, 028001. [CrossRef]

29. Bai, Z.; Long, M.; Chen, L.; Chen, M.; Li, G. 145-watt high beam quality bidirectional voltage-supplied Q-switched Nd:YAG master oscillator power amplifier laser. Opt. Eng. 2013, 52, 024202. [CrossRef]

30. Wada, K.; Cho, Y. Improved expression for the time-bandwidth product of picosecond optical pulses from gain-switched semiconductor lasers. Opt. Lett. 1994, 19, 1633-1635. [CrossRef] [PubMed]

31. Bai, Z.; Bai, Z.; Yang, C.; Chen, L.; Chen, M.; Li, G. High pulse energy, high repetition picosecond chirped-multi-pulse regenerative amplifier laser. Opt. Laser Technol. 2013, 46, 25-28. [CrossRef]

(C) 2017 by the authors. Licensee MDPI, Basel, Switzerland. This article is an open access article distributed under the terms and conditions of the Creative Commons Attribution (CC BY) license (http://creativecommons.org/licenses/by/4.0/). 